\title{
Publisher Correction: Affinity purification of cell-specific mitochondria from whole animals resolves patterns of genetic mosaicism
}

Arnaud Ahier, Chuan-Yang Dai, Andrea Tweedie, Ayenachew Bezawork-Geleta, Ina Kirmes and Steven Zuryn (D)

Correction to: Nature Cell Biology https://doi.org/10.1038/s41556-017-0023-x, published online 22 January 2018.

In the version of this Technical Report originally published, chromosome representations (indicated by black lines) were missing from Fig. 2a due to a technical error. The corrected version of Fig. $2 \mathrm{a}$ is shown below. This has now been amended in all online versions of the Technical Report.
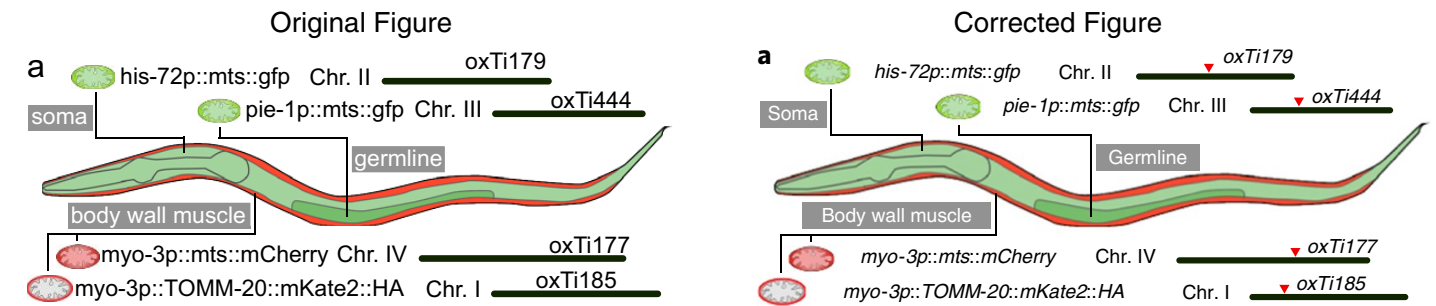

Fig. 2a | Original and corrected panels.

Published online: 15 February 2018

https://doi.org/10.1038/s41556-018-0055-x 